\title{
PENGGUNAAN PASIR DAN KERIKIL LOKAL DI KABUPTEN SUMENEP SEBAGAI BAHAN MATERIAL BETON DI TINJAU DARI MUTU KUAT BETON
}

\author{
Oleh : Soeparno dan Didiek Purwadi *)
}

\begin{abstract}
Abstrak :
Dalam pembangunan fisik infrastruktur tiap daerah cenderung memanfaatkan sumber alam yang digunakan sebagai bahan bangunan yang merupakan salah satu dampak dari Otonomi Daerah (otoda). Sehingga penggunaan material bahan bangunan akan berdampak pada pada kualitas maupun umur bangunan khususnya beton struktur. Permasalahan yang cukup menarik yaitu layakkah bahan bangunan yang menggunakan material pasir dan kerikil lokal di kabupaten Sumenep sebagai bahan bangunan struktur.

Oleh sebab itu, mutu bahan agregat dapat ditentukan antara lain dengan komposisi kimia, petrografik, klasifikasi, berat jenis, kekuatan, ketahanan, porositas dan lain-lain. Untuk dapat mengetahui mutu vahan, maka harus memenuhi standart kualitas antara lain: standart ASTM, SNI dan British Standart dan lain sebagainya.

Dari hasil pengujian yang dilakukan di laboraturium diambil suatu rekomendasi antara lain: Bahan bangunan kerikil dan pasir hanya dapat digunakan untuk kontruksi: a). perlu diadakan pencucian agar bahan tersebut bersih b). Dan lebih baik sebelum menggunakan bahan bangunan agar dapat memenuhi peryaratan, harus dilakukan uji laboraturium.
\end{abstract}

Kata Kunci: material, agregat, konstruksi standart,keikil, petrografik

\section{PENDAHULUAN}

Kabupaten Sumenep dari tahun ke tahun terus mengadakan pembangunan terutama bangunan fisik. Oleh karena kondisi alam yang ada antara lain sumber daya alam penghasil bahan bangunan atau material kerikil dan pasir yang cukup berbeda dengan material yang berasal dari pulau Jawa yang telah teruji mutunya sebagai bahan bangunan. Penggunaan material tersebut akan berdampak pada pada kualitas maupun umur bangunan khususnya beton. Dari uraian singkat tersebut, maka dapat diambil suatu permasalahan yang perlu diadakan penelitian yang cukup menarik yaitu berapakah mutu kuat beton yang menggunakan material pasir dan kerikil lokal di kabupaten Sumenep.

Untuk mengetahui mutu kuat beton menurut standar Nasional Indonesia (SNI) dengan menggunakan bahan material pasir dan kerikil lokal Sumenep tersebut, maka perlu diadakan uji kuat tekan dan tarik belah. Pengujian dilakukan di laboraturium dengan mengambil sampel material dengan menggunakan porposive sampling. Dari material sampel yang diambil di bawa ke laboraturium bahan Jurusan Teknik Sipil FT Unesa dan dibuat sejumlah benda uji beton yang berbentuk tabung dan dirawat hingga umur 28 hari dan selanjutnya diadakan uji kuat tekan dan tarik belah.
Dari pengujian akan didapat akan kuat tekan $\left(\boldsymbol{f}_{\boldsymbol{x}}\right)$ dan kuat tarik belah $\left(\boldsymbol{f}_{c t}\right)$ dari masing-masing sampel dan selanjutnya dapat dianalisis perilaku kuata tekan dan belah tarik dan berapa mutu kuat tekan dan tarik belah beton dengan menggunakan pasir dan kerikil lokal Sumenep. Dari hasil pengujian tersebut, maka dapat dipakai sebagai bahan informasi dan rekomendasi kepada instansi terkait tentang penggunaan material pasir dan kerikil lokal dari Sumenep. Dari hasil penelitian dapat pula digunakan sebagai dasar tindak lanjut penelitian atau penelitian serupa untuk mortal (spesi) atau yang lain yang berkaitan dengan bahan material tersebut untuk mengetahui: a) hasil kuat tekan mortal yang menggunakan bahan pasir lokal di Sumenep b). hasil kuat tekan Beton yang menggunakan bahan pasir dan kerikil lokal di Sumenep. c). apakah Mortal dan Beton yang menggunakan material pasir dan kerikil dari kabupaten Sumenenep memenuhi syarat sebagai bahan bangunan. Diharapkan manfaat dari penelitian ini adalah a). memberikan informasi dan rekomendasi kepada pembuat kebijakan tentang mutu pasir dan kerikil lokal apabila digunakan sebagai bahan bangunan.

\footnotetext{
*) Dosen Teknik Sipil

Universitas Negeri Surabaya
} 
b)dapat digunakan bahan kajian awal tentang penggunakan material pasir dan kerikil lokal selanjutnya.

\section{Perumusan Masalah}

Apakah bahan Bangunan (material) lokal yang berasal dari wilayah kabupaten Sumenep memenuhi standart untuk digunakan sebagai bahan beton struktur?

\section{Tujuan}

Untuk mengetahui kualitas bahan bangunan ( material ) yang berasal dari wilayah kabupaten Sumenep memenuhi standart SKKNI.

\section{KAJIAN PUSTAKA}

\section{Bahan dasar beton}

Beton didapat dari pencampuran bahanbahan agregat halus dan kasar yaitu pasir, batu pecah, atau bahan semacam lainya, dengan menambahkan pembantu lainya guna keperluan perekat (semen) dan air sebagai bahan pembantu proses kimiawi selama proses pengerasan dan perawatan. Agreagat halus dan kasar sebagai bahan susun kasar campuran, yang merupakan komponen utama beton.

\section{a. Agregat halus}

Agragat halus (pasir) adalah bahan batuan halus terdiri dari butiran dengan partikel-partikel yang leawat saringan 4 atau $5 \mathrm{~mm}$ yang diperoleh dari disintegrasi batuan alam. Agregat halus halus untuk bahan bangunan dapat berupa pasir alam atau pasir buatan yang dihasilkan oleh alat pemecah batu.

Adapun syarat-syarat yang harus dipenuhi adalah:

1) Teridir dari butiran keras dan tajam serta bersifat kekal (tidak pecah dan hancur) terhadap pengaruh cuaca.

2) Harus berasih atau tidak mengandung lumpur dengan toleransi yang di ijinkan lebih dari $5 \%$ (ditentukan dari berat kering).

3) Tidak boleh mengandung bahanbahan organic dan asam terlalu banyak.

4) Mempunyai ukuran butiran yang beraneka ragam.

\section{b. Agregat Kasar}

Agregat kasar yang biasanya disaebut dengan kerikil atau batu pecah. Kerikil adalah bahan yang terjadi sebagai bahan hasil disintegrasi alami dari batu-batuan dan berbentuk agak bulat-bulat serta memiliki permukaan agak licin. Sedangkan batu pecah adalah bahan berbentuk pecahanpecahan yang dihasilkan dari proses penggilingan/pemecah batu dengan ukuran rata-rata $5-70 \mathrm{~mm}$.

Adapaun syarat-sayarat agregat kasar:

1) Harus terdiri dari butir-butir keras dan tidak berpori dan bersifat kekal (tidak pecah dan hancur) tehadap cuaca.

2) Tidak boleh mengandung Lumpur lebih dari $1 \%$ (ditentukan dari berat kering).

3) Berukuran beraneka ragam (heterogen)

4) Tidak diijinkan mengandung zat-zat yang dapat merusak beton antara lain zat alkali.

5) Ukuran maksimum tidak boleh lebih dari pada 1/5 dari jarak terkecil antara bidang-bidang samping cetakan (begestig) dan $1 / 3$ dari tebal plat atau $3 / 4$ dari jarak bersih minimum diantara penulangan.

\section{c. Semen}

Semen adalah merupakan bahan perekat hidrolis yang dihasilkan dari penggilingan klinker yang kandungan utama kalsium silikat dan satu atau dua buah bentuk kalsium sulfat sebagai bahan tambahan. Semen juga memiliki sifat adhesif dan kohesif yang mengikat unsur-unsur mineral lainya menjadi satu masa yang padat jika dicampur dengan air.

\section{d. Air}

Beton akan mengalami proses pengerasan apabila telah terjadi reaksi antara air dan semen. Oleh karena semen apabila ditambah dengan air akan terjadi reaksi antara komponenkomponen semen dan air yang disebut dengan hidrasi. Reaksi hidrasi ini dipengaruhi oleh kehalusan butiran semen, jumlah air, suhui dan sebagaiya. Sehingga air juga harus memenuhi syarat antara lain:

1) Tidak boleh mengandung minyak, asam alkali, garam, dan bahan alin yang dapat merusak beton.

2) Yang pada intinya air yang digunakan untuk campuran beton 
adalah air yang memenuhi syarat sebagai air minum.

\section{Kuat Beton}

\section{a. Kuat tekan}

Kuat tekan beton adalah kemampuan beton menerima beban aksial (tekan) maksimum, biasanya mualai umur beton 28 hari. Kekuatan tekan merupakan sifat fisik yang utama dari beton dan digunakan dalam perencanaan berbagai struktur. Kuat tekan beton juga dijadikan dasar dalam perhitungan kekuatan yang lain seperti kekuatan tarik, kekuatan geser serta modulus elastisitas.

Nilai kuat tekan beton didapatkan melalui tata cara pengujian standar yaitu mesin uji dengan memberikan beban tekan bertingkat dengan kecepatan peningkatan beban tertentu diatas benda uji. Menurut Dipohusodo, Istiawan, 1997: bahwa tegangan fx' (nilai kuat tekan), bukanlah tegangan yang timbul pada saat benda uji hancur melainkan tegangan maksimum pada saat regangan beton mencapai nilai $\pm 0,002$.

\section{b. Kuat Tarik belah}

Kuat tarik beton adalah merupakan sifat penting yang berpengaruh terhadap perambatan dan ukuran retak (cracking) dari suatu struktur bangunan. Nilai kuat tarik beton mempunyai nilai lebih rendah dibanding dengan kuat tekan. Perkiraan secara kasar adalah berkisar antara $9 \%-15 \%$ dari kuat tekanya (Dipohusodo, Istiawan, 1997). Keretakan dalam suatu struktur merupakan awal dari suatu keruntuhan bangunan. Kuat tarik belah merupakan pengukuran kuat tarik beton secara tidak langsung.

\section{Teknik Analisis Data}

Teknik analisis data menggunakan analisis diskriptif kuantitatif, dengan menghitung dan mengamati hasil uji dari masing-masing benda uji sebagai berikut:

\section{a. Kuat Tekan}

Menghitung kuat tekan beton dengan menggunakan rumus :

$$
f_{c}=\frac{P}{A}
$$

\section{Dimana :}

$\mathrm{fC}^{\prime}=$ Kuat tekan beton $\left(\mathrm{kg} / \mathrm{cm}^{2}\right.$ MPA

${ }_{\mathrm{P}}=$ Gaya Tekan $(\mathrm{N}, \mathrm{Kg})$

$\mathrm{A}=$ Luas penampang benda uji (cm, $\mathrm{mm}$ )

b. Kuat Tarik

Untuk menghitung kuat tarik belah beton dengan menggunaan rumus perhitungan :

$$
f_{c t}=\frac{2 P}{L . D} \ldots \ldots \ldots \ldots(2)
$$

\section{Dimana :}

$\boldsymbol{f}_{c t}=$ Kuat tarik belah beton $\left(\mathrm{kg} / \mathrm{cm}^{2}\right.$, MPA)

$\mathrm{P}=$ Beban pada waktu belah $(\mathrm{N}$, $\mathrm{Kg})$

$\mathrm{L} \quad=$ Panjang benda uji $(\mathrm{cm}, \mathrm{mm})$

$\mathrm{D}=$ Diameter benda uji silinder $(\mathrm{cm}, \mathrm{mm})$

c. Pengujian kandungan lumpur dan bahan organik.

d. Pengujian ayakan atau susunan agregat kasar (kerikil) dan halus (pasir)

\section{HASIL DAN PEMBAHASAN}

\section{Agregat Halus}

a. Pengujian kotoran organik dalam pasir

1) Data hasil pengujian:

Volume pasir $\quad=130 \mathrm{cc}$

Volume $\mathrm{NaOH} 3 \%=250 \mathrm{cc}$

2) Hasil pengujian:

Warna yang terjadi pada larutan $\mathrm{NaOH} 3 \%$ setelah didiamkan selama 24 jam, menimbulkan warna menjadi lebih pekat dari standart warna.

\section{Pengujian kadar lumpur dalam} pasir

b. Data hasil pengujian:

Berat kerikil mula - mula $A=100$ gram

Berat kerikil bersih oven $B=986$ gram

Prosentase kadar lumpur $=\times 100$ $\%=x 100 \%=14 \%$

\section{c. Hasil pengujian:}

Kadar lumpur yang dikandung oleh kerikil hasil pengujian adalah lebih dari $5 \%$ sesuai dengan yang 
diisyaratkan dalam PBI1971 pasal 3.3ayat 3.

\section{Susunan butir}

Agregat halus harus mempunyai susunan besar butir (grading) dalam batasan-batasan sebagai berikut:

Tabel 1. Susunan Besar Butir (Grading)

\begin{tabular}{ccc}
\hline Ukuran lubang ayakan $(\mathbf{m m})$ & Presen lolos kumulatif & Hasil \\
\hline 9.5 & 100 & 100 \\
4.74 & $95-100$ & 100 \\
2.36 & $80-100$ & 100 \\
1.18 & $60-85$ & 93 \\
0.60 & $30-60$ & 80 \\
0.30 & $10-30$ & 40 \\
0.15 & $2-10$ & 24 \\
\hline
\end{tabular}

Sumber: Hasil Pengujian.

\section{Agregat Kasar}

a. Analisa saringan dan perhitungan modulus kehalusan

Hasil dari analisa saringan dan perhitungan modulus kehalusan dapat dilihat pada tabel 4.4. berikut:

Tabel 2. Analisa Saringan dan Perhitungan Modulus Kehalusan

\begin{tabular}{|c|c|c|c|c|c|c|c|}
\hline \multirow{2}{*}{$\begin{array}{c}\text { Campur } \\
\text { Pembatasan }\end{array}$} & \multirow{2}{*}{$\begin{array}{c}\text { Ukuran } \\
\text { Saringan ASTM }\end{array}$} & \multicolumn{2}{|c|}{$\begin{array}{c}\text { Pasir } \\
\text { Kumulatif \% }\end{array}$} & \multicolumn{2}{|c|}{$\begin{array}{c}\text { Kerikil } \\
\text { Kumulatif \% }\end{array}$} & \multicolumn{2}{|c|}{$\begin{array}{c}\text { Gabungan } \\
\text { Kumulatif \% }\end{array}$} \\
\hline & & Tertahan & Lewat & Tertahan & Lewat & Tertahan & Lewat \\
\hline $98-100$ & $1,5 "(3)$ & & 100 & 6 & 94 & 2 & 98 \\
\hline $68-80$ & $3 / 4 "(20)$ & & 100 & 41 & 59 & 24 & 76 \\
\hline $47-57$ & $3 / 8 "(10)$ & 0 & 100 & 78 & 22 & 38 & 62 \\
\hline $35-45$ & No.4 (4.16) & 0 & 100 & 92 & 8 & 55 & 45 \\
\hline $28-36$ & No.8 & 0 & 100 & 100 & 0 & 63 & 37 \\
\hline $18-27$ & No.16 & 3 & 93 & 100 & 0 & 77 & 23 \\
\hline $11-19$ & No.30 & 24 & 76 & 100 & 0 & 92 & 8 \\
\hline $2-8$ & No.50 & 37 & 63 & 100 & 0 & 97 & 3 \\
\hline $1-2$ & No.100 & 52 & 48 & 100 & 0 & 100 & 0 \\
\hline Modulu & Kehalusan & 3,01 & & 7,34 & & 5,61 & \\
\hline
\end{tabular}

Sumber: Hasil Pengujian.

\section{Pengujian kadar lumpur kerikil}

a. Data hasil pengujian:

Berat kerikil mula-mula $A=1000$ gram

Berat kerikil bersih oven $B=972$ gram

Prosentase kadar lumpur $=\mathrm{x}$ $100 \%=x 100 \%=28 \%$

b. Hasil pengujian:

Kadar lumpur yang dikandung oleh kerikil hasil pengujian adalah lebih dari $1 \%$ sesuai dengan yang diisyaratkan dalam PBI 1971 pasal 3.3 ayat 3 , disimpilkan tidak dapat memenuhi syarat tidak layak sebagai bahan bangunan.

\section{Pasir dan Kerikil}

a. Data hasil pengujian ayakan pasir.
Tabel 3. Hasil Analisa Ayakan Pasir

\begin{tabular}{lllll}
\hline \multirow{2}{*}{ Ayakan No } & \multicolumn{2}{c}{ Tertinggal } & \multicolumn{2}{c}{ Komulatif } \\
& Gram & $\%$ & Tertinggal & Lolos \\
\hline 4 & 38,90 & 7,78 & 7,78 & 92,22 \\
8 & 30,10 & 6,02 & 13,80 & 86,20 \\
16 & 43,40 & 8,68 & 22,48 & 77,52 \\
30 & 120,55 & 24,11 & 46,59 & 53,41 \\
50 & 220,40 & 44,08 & 90,67 & 9,33 \\
100 & 41,90 & 8,38 & 99,05 & 0,95 \\
Pan & 4,75 & 0,95 & 0 & 0 \\
Jumlah & 500 & 100 & 280,37 &
\end{tabular}

Sumber : Hasil Pengujian.

b. Disiapkan data-data analisa ayakan kerikil : 
Tabel 4. Hasil Ayakan Kerikil

\begin{tabular}{lllll}
\hline \multirow{2}{*}{ Ayakan No } & \multicolumn{2}{c}{ Tertinggal } & \multicolumn{2}{c}{ Komulatif } \\
& Gram & $\%$ & Tertinggal & Lolos \\
\hline $1.5 "$ & 993 & 6,21 & 6,21 & 93,79 \\
$1 "$ & 0 & 0 & 0 & 0 \\
$3 / 4$. & 8691 & 54,32 & 60,53 & 39,47 \\
$1 / 2 "$ & 0 & 0 & 0 & 0 \\
$3 / 8 "$ & 4671 & 29,19 & 89,72 & 10,28 \\
No.4 & 1436 & 8,98 & 98,70 & 1,30 \\
8 & 209 & 1,30 & 100 & 0 \\
16 & 0 & 0 & 100 & 0 \\
30 & 0 & 0 & 100 & 0 \\
50 & 0 & 0 & 100 & 0 \\
100 & 0 & 0 & 100 & 0 \\
Pan & 0 & 0 & 0 & 0 \\
Jumlah & 16000 & 100 & 755,16 & \\
\hline Sumber & Hasil Peng &
\end{tabular}

Sumber: Hasil Pengujian.

c. Direncanakan campuran pasir dan kerikil yang tertinggal pada ayakan 4,76 $\mathrm{mm}$ sebesar:
$Y p=$ adalah agregat halus yang tertinggal pada ayakan $4,76 \mathrm{~mm}=$ $7,78 \%$

$\mathrm{Yk}=$ adalah agregat kasar yang tertinggal pada ayakan $4,76 \mathrm{~mm}=$ $98,70 \%$

Persamaan dasar

$A=3500$

$3500=7,78 x-98,70 x+9870$

$3500=-90,92 x+9870$

$90,92 x=6370$

$$
x=70 \%
$$

Hasil: Prosentase pasir $=30 \%$

Prosentase kerikil $=70 \%$

Sebelum diplot dalam grafik maka dihitung dulu kedalam tabel campuran antara pasir dan kerikil.

Tabel 5. Tabel Analisa Ayakan Campuran

\begin{tabular}{llllll}
\hline \multicolumn{1}{c}{$\begin{array}{c}\text { Lubang } \\
\text { ayakan }\end{array}$} & \multicolumn{1}{c}{$\begin{array}{c}\text { Pasir Komulatif } \\
\text { tinggal }\end{array}$} & \multicolumn{1}{c}{$\begin{array}{c}\text { Kerikil komulatif } \\
\text { tinggal }\end{array}$} & $\begin{array}{c}\text { Campuran Pasir + Kerikil } \\
\text { Pasir } \\
\mathbf{3 0 \%}\end{array}$ & $\begin{array}{c}\text { Kerikil } \\
\mathbf{7 0} \%\end{array}$ & Jumlah \\
\hline $3 "$ & & & & 4,34 & 4,34 \\
$11 / 2 "$ & & 6,21 & & 42,37 & 42,37 \\
$1 / 2 "$ & & 60,53 & & 62,80 & 62,80 \\
$3 / 8 "$ & & 89,72 & 2,33 & 69,09 & 71,42 \\
$4,76 \mathrm{~m}$ & 7,78 & 98,70 & 4,14 & 70 & 74,14 \\
$2,38 \mathrm{~mm}$ & 13,80 & 100 & 6,74 & 70 & 76,74 \\
$1,19 \mathrm{~mm}$ & 22,48 & 100 & 13,97 & 70 & 83,97 \\
$0,59 \mathrm{~mm}$ & 46,59 & 100 & 27,20 & 70 & 97,20 \\
$0,297 \mathrm{~mm}$ & 90,67 & 100 & 29,71 & 70 & 99,71 \\
$0,149 \mathrm{~mm}$ & 99,05 & 100 & 0 & 0 & 0 \\
Pan & 0 & 0 & & & 612,69 \\
Jumlah & 280,37 & 755,16 & & & \\
FM & 2,80 & 7,55 & & & \\
\hline
\end{tabular}

Sumber: Hasil Pengujian.

\section{Berdasarkan tabel 4.7. tentang modulus kehalusan butir kerikil untuk diameter maksimum 11/2" maka FM minimum 7,55 dan untuk ini maka hasil dari campuran diatas termasuk baik karena 6,12 $>5,40$.... Oke.}

\section{Pembahasan:}

Yang perlu diperhatikan adalah analisa ayakan dari kedua bahan tersebut, apakah pada analisa ayakan pasir termasuk zona berapa, atau analisa ayakan kerikil pada daerah: a, b, c, d.

\section{Perbandingan Agregat Halus dan Agregat Kasar}

Dari hasil analisa saringan dan perhitungan modulus kehalusan, kita dapat tentukan porsi masing-masing agregat dengan cara grafis, yaitu dengan menarik garis miring yang menggabungkan komulatif \% lewat pasir dengan kerikil pada setiap ukuran saringan sesuai campur pembatasannya..

Dari gambar diatas diperoleh hasil $30 \%$ agregat halus dan $70 \%$ agregat kasar, sehingga diperoleh agregat gabungan yang memenuhi persyaratan batas degradasinya, yang dapat dilihat pada gambar 4.2. berikut:

\section{SIMPULAN DAN SARAN}

\section{Simpulan}

Dari analisis dengan menghitung dan mengamati hasil uji laboraturium dari masing-masing benda uji dan 
dibandingkan dengan standart yang diijinkan atau disyaratkan, maka dapat dibuat suatu simpulan sebagai berikut:

\section{a. Agregat Halus}

Syarat agregat halus menurut SII 0052-80 dapat dilihat pada tabel berikut :

\section{Tabel 6. Syarat Mutu Agregat Halus Menurut SII 0052 - 80}

\begin{tabular}{|c|c|c|c|}
\hline NO & URAIAN & SYARAT & HASIL \\
\hline 1 & $\begin{array}{l}\text { Modulus } \\
\text { kehalusan }\end{array}$ & $1.5-3.8$ & $3,01 \%$ \\
\hline \multirow[t]{3}{*}{2} & $\begin{array}{l}\text { Sifat kekal } \\
\text { benda diuji } \\
\text { dengan } \\
\text { larutan garam }\end{array}$ & & \\
\hline & $\begin{array}{l}\text { sulfat: } \\
\text { a. Natrium }\end{array}$ & $<10 \%$ & $13 \%$ \\
\hline & $\begin{array}{l}\text { Sulfat } \\
\text { b. Magnesium } \\
\text { Sulfat }\end{array}$ & $<15 \%$ & $19 \%$ \\
\hline 3 & $\begin{array}{l}\text { Kadar zat } \\
\text { organik } \\
\text { ditentukan } \\
\text { dengan } \\
\text { larutan sulfat } \\
3 \%\end{array}$ & $\begin{array}{l}\text { Warna } \\
\text { standart }\end{array}$ & $\begin{array}{l}\text { Lebih } \\
\text { Pekat }\end{array}$ \\
\hline 4 & Kadar lumpur & $5 \%$ & $14 \%$ \\
\hline
\end{tabular}

Sumber: Hasil pengujian.

Dari hasil pengujian laboraturium untuk agregat halus (pasir) dan dibandingkan dengan syarat dari SII 0053-80 hanya modulus kehalusan saja yang memenuhi sedangkan yang lain tidak berati kurang memenuhi syarat.

\section{b. Agregat Kasar}

Syarat mutu untuk agregat kasar menurut SII 0052-80 dapat dilihat pada tabel 5.2. berikut:
Tabel 7. Syarat Mutu Agregat Kasar Menurut SII 0052 - 80

\begin{tabular}{|c|c|c|c|}
\hline NO & URAIAN & SYARAT & HASIL \\
\hline 1 & $\begin{array}{l}\text { Modulus } \\
\text { kehalusan }\end{array}$ & $6.0-7.1$ & 3,6 \\
\hline 2 & $\begin{array}{l}\text { Kekerasan } \\
\text { dengan batu } \\
\text { dinding dengan } \\
\text { pasir bangka }\end{array}$ & $<2,2$ & 4,3 \\
\hline 3 & $\begin{array}{l}\text { Kekerasan Los } \\
\text { Angles }\end{array}$ & Tabel & $\begin{array}{l}\text { Lihat } \\
\text { tabel }\end{array}$ \\
\hline 4 & Batu Pipih & $<20 \%$ & $18,6 \%$ \\
\hline 5 & $\begin{array}{l}\text { Sifat kekal } \\
\text { benda diuji } \\
\text { dengan larutan } \\
\text { garam, sifat: }\end{array}$ & & \\
\hline & $\begin{array}{l}\text { a. Natrium } \\
\text { Sulfat }\end{array}$ & $<12 \%$ & $14,6 \%$ \\
\hline & $\begin{array}{l}\text { b. Magnesium } \\
\text { Sulfat }\end{array}$ & $<18 \%$ & $21,3 \%$ \\
\hline 6 & $\begin{array}{l}\text { Susunan } \\
\text { Grading }\end{array}$ & Tabel & $\begin{array}{l}\text { Lihat } \\
\text { table }\end{array}$ \\
\hline 7 & Kadar Lumpur & $1 \%$ & $6,8 \%$ \\
\hline
\end{tabular}

Dari hasil pengujian laboraturium untuk agregat halus (pasir) dan dibandingkan dengan syarat menurut SII 0052-80, dapat disimpulkan bahwa kerikil yang digunakan untuk bahan bangunan dari wilayah kabupaten sumenep kurang memenuhi syarat.

\section{Saran}

Bahan bangunan kerikil dan pasir dari daerah Sumenep dapat digunakan untuk kontruksi :

a. Untuk dapat diadakan pengujian yang bersifat pengalaman alat sederhana. memenuhi peryaratan maka pasir dan kerikil dari daerah Sumenep untuk diadakan pencucian agar bahan tersebut bersih dari bahan kotoran /organik maupun kandungan lumpur.

b. Untuk memenuhi syarat keras untuk bahan maka perlu diadakan pemilihan secara kasat mata dan peratan yang sederhana.

c. Dan lebih baik sebelum menggunakan bahan bangunan yang berasal dari daerah Sumenep agar memenuhi peryaratan harus dilakukan uji laboraturium. 


\section{DAFTAR PUSTAKA}

Anonim, Kabupaten Sumenep dalam angka 2006, Badan Pusat statistik kabupaten Sumenep Dipohusodo, Istiawan, 1997. Struktur Beton Bertulang, PT. Gramedia Pusaka Jakarta

SKSNI T-15-1991-03 Tata Cara Perencanaan Struktur Beton untuk Bangunan Gedung. DPU Bandung 